\title{
Estudio sociolingüístico del discurso reproducido en el corpus oral PRESEEA-Sevilla
}

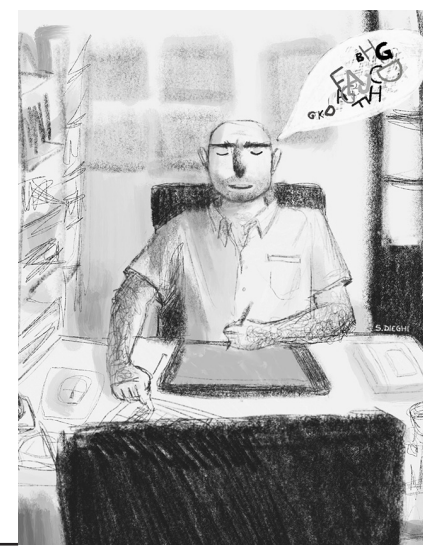

Doina Repede

Universidad de Sevilla, España

doinarepede@gmail.com

Trabajo recibido el 5 de marzo de 2019 y aprobado el 13 de junio de 2019.

\section{Resumen}

El objetivo de este artículo consiste en describir el uso del discurso reproducido en 72 entrevistas semidirigidas pertenecientes al corpus oral PRESEEA-Sevilla. Para conseguir nuestro objetivo, tomamos en consideración distintos criterios lingüísticos, pragmáticos y sociales. Los resultados obtenidos muestran una preferencia por el uso del discurso directo por parte de los informantes entrevistados. El marco introductor favorecido es el canónico, esto es, mediante un verbo, y decir es el más empleado para introducir las citas. Además, los hablantes sevillanos prefieren referir las palabras propias y/o ajenas de forma directa. La función pragmática más frecuente de las citas es relatar experiencias personales y/o ajenas, anécdotas, etc., seguida por la de argumentar. Por factores sociales, son la segunda generación y las mujeres quienes muestran mayor tendencia al uso del discurso referido. Según el nivel de instrucción de los informantes, el empleo de este mecanismo se correlaciona con el sociolecto bajo. Asimismo, predomina el empleo del discurso referido cuando los dos participantes en la interacción se conocen.

\section{A sociolinguistic study of the reported speech use in the PRESEEA- Seville oral corpus}

\begin{abstract}
The aim of this study is to describe the reported speech use in a sample of 72 oral semi-controlled interviews taken from the PRESEEA-Seville oral corpus; we based our study on linguistic, pragmatic and social criterions. The results showed that the questioned informants preferred to use direct speech. The most frequently introducing frame was the canonic one, that means, with a verb, and decir was the most employed verb to report. The Sevillian speakers prefer to report their own and/or others' words by using direct reported speech. The most frequent pragmatic function is to narrate personal experiences, anecdotes, etcetera. Regarding the social
\end{abstract}

Palabras clave

discurso directo discurso indirecto entrevistas semidirigidas PRESEEA-Sevilla Sociolingüística

Keywords

direct reported speech indirect reported speech semi-controlled interviews PRESEEA-Seville Sociolinguistics 
factors, the second generation and women showed a bigger tendency to the reported speech use. According to the informants' educational level, the employ of this mechanism is correlated to low sociolect. It was also noticed that the reported speech predominates when the participants joining the conversation know each other.

\section{Estudo socioliguístico do discurso reproduzido no corpus oral PRESEEA-Sevilha}

\section{Resumo}

O objetivo deste artigo é descrever o uso do discurso reproduzido em 72 entrevistas semi-dirigidas pertencentes ao corpus oral PRESEEA-Sevilla. Para atingir nosso objetivo, levamos em consideração diferentes critérios lingüísticos, pragmáticos e sociais. Os resultados obtidos mostram uma preferência pelo uso do discurso direto pelos informantes entrevistados. O quadro introdutório mais utilizado é o canônico, isto é, por meio de um verbo, e dizer é o mais usado para introduzir as palavras reproduzidas. Além disso, os falantes sevilhanos preferem referir suas próprias palavras e / ou estrangeiras usando a discurso direto. A função pragmática mais frequente das citações é relacionar experiências pessoais e / ou de outras pessoas, anedotas, etc. Por fatores sociais, eles são a segunda geração e as mulheres que mostram a maior tendência a usar o discurso reproduzido. De acordo com o nível de instrução dos informantes, o uso desse mecanismo está correlacionado com o baixo socioleto. Da mesma forma, o uso do discurso referido predomina quando os dois participantes da interação se conhecem.

\section{Introducción ${ }^{1}$}

Como concepto general, el discurso referido (en adelante el DR) se define como "un recurso lingüístico que permite a los hablantes recrear una situación discursiva, lo que se materializa mediante la reproducción de los enunciados proferidos por las voces intervinientes en la situación evocada y la reconstrucción del correspondiente contexto de enunciación” (San Martín y Guerrero 2013, 260). De acuerdo con Gallucci (2018a, 56), todo ello posibilita "que dentro del DR se integren elementos discursivos procedentes de actos de enunciación ajenos efectiva y realmente proferidos, o bien recreados e imaginados por el propio acto de enunciación”.

Asimismo, el DR presenta, entre otras, dos variantes básicas de integración textual: el discurso directo (DD) y el discurso indirecto (DI). El primero se define como "un procedimiento mediante el cual quien habla (o escribe) incorpora a su discurso una secuencia textual, de procedencia propia o ajena, que es presentada como si supuestamente fuera reproducida de modo literal” (San Martín y Guerrero 2013, 260). Este mecanismo citativo está formado por "una expresión introductora (EI) que contiene un verbo de 'decir' flexionado y una 'cita directa' (CD), marcada tipográficamente por guiones o comillas” (Maldonado 1999, 3554) y que siempre reproduce el contenido de un enunciado realizado verbalmente con anterioridad. "La expresión introductora y la cita directa están separadas por una pausa, marcada tipográficamente por los dos puntos” (ibídem):

\section{Palavras-chave}

discurso direto discurso indireto entrevistas semi-dirigidas PRESEEA-Sevilla Sociolinguística

1. Este trabajo se ha realizado dentro del proyecto Patrones Sociolingüísticos del Español de Sevilla (Ref. FFI2015-68171-C5-3-P), financiado por el Ministerio de Economía y Competitividad de España y por el Fondo Europeo de Desarrollo Regional (MINECO/FEDER, UE). 
I: una camiseta que se compró mi madre < vacilación/> le compró mi madre por reyes a mi padre / una XL

E: uhum

I: que supuestamente le tendría que estar bien / cuando se la puso dice </cita> pero si aquí no quepo </cita>

E: ¿sí?

I: o sea que ya te engañan / más que nada ya te engañan

E: ya (SEVI_H21_027).

No obstante, "Es importante aclarar que esto último se da en el caso de la escritura, [...] pero en el caso de la oralidad esta relación entre la EI y la CD es de carácter prosódico y contextual” (Grajales Alzate 2017, 224):

no teníamos rumbo <alargamiento/ $><$ risas = "E"/> / no es broma ¿eh? $<$ risas = "todos"/> / <cita> Canija ipara dónde vamos / para la izquierda o a la derecha? </cita> / $<$ cita> pues < vacilación/> pues < vacilación/> pues tira para la izquierda </cita> / y cuando teníamos ganas de comer parábamos / y cuando no <risas = "l”/> / pues no parábamos / y gastábamos gasolina (SEVI_H22_031) ${ }^{2}$.

Por su parte, el DI “está constituido por una 'expresión introductora' (El) que contiene un verbo de decir flexionado y una 'cita indirecta' (CI) cuya marca es la conjunción que, y que está subordinada al verbo de la expresión introductora" (Maldonado 1999, 3554).

I: creo que lo nervioso que yo soy / era el que más tranquilo estaba en ese momento / entre otras cosas / eh la alférez quería tirar mi dedo

E: jah! ¿sí?

I: sí sí / no / que lo tiró / vamos / y yo le pregunté que dónde estaba mi dedo / que yo que $<$ vacilación/> / porque me querían<alargamiento/> cerca de < vacilación/> de donde esta<palabra_cortada/ > / bueno cerca / estábamos haciendo unas maniobras y estaba el Príncipe / el portaaviones Príncipe de Asturias estaba por allí (SEVI_H22_031).

Como ya se ha apuntado en otros trabajos (Repede 2017b, Gallucci 2018b), el estudio del discurso referido se ha llevado a cabo sobre todo en los textos escritos, entre ellos, literarios (Álamo, 2013; Girón Alconchel, 1989; Ruano San Segundo, 2015, etc.) o periodísticos (Méndez, 1999, 2000; Casado, 2010; Casado y de Lucas, 2013; de Lucas 2017; Repede, 2015a; 2015b; 2017a; etc.). Todo ello puede estar relacionado, como afirma Gallucci (2018b, 143), con "la dificultad que supone recolectar corpus orales" y con el hecho de que "el análisis de las conversaciones siempre suele ser más complejo en virtud del alto grado de indefinición, imprevisibilidad e improvisación por parte de quienes intervienen en ellas" (ibídem). Por tanto,

estas circunstancias han dificultado la comprensión cabal de la reproducción del discurso en la oralidad que, como es bien sabido, constituye la primera etapa en el proceso de evolución de la lengua y el registro fundamental a través del cual nos comunicamos en la vida cotidiana (Gallucci, 2018b, 143).

Sin embargo, el discurso referido como mecanismo citativo en la oralidad parece haber suscitado últimamente el interés de los investigadores, de modo que se han llevado a cabo estudios sobre este fenómeno en las distintas variedades del español hablado. Así, para el español peninsular, se han centrado en el discurso reproducido Girón Alconchel (1988), Benavent (2003, 2015), Camargo (2004), Repede (2017b, 2018b), entre
2. El código del final de los ejemplos debe leerse de la siguiente forma: i) SEVI=Sevilla; ii) sexo: $\mathrm{H}=$ hombre, $\mathrm{M}=$ mujer; iii) edad: $1=20$ a 34 años, $2=35$ a 54 años, $3=55$ años en adelante; iv) grado de instrucción: $1=$ sin estudios o con estudios básicos; $2=$ estudios medios; 3 = estudios superiores; $v$ ) identificación del hablante dentro del corpus: 001, 002, 003...049, 050, 051, etc. Sobre las convenciones de transcripción de las entrevistas, véase Repede (2019 y en prensa). 
otros. Para el español de América, mencionamos, entre otros, las investigaciones de Van der Houwen (2000) en la Ciudad de México; Gallucci (2009, 2013, 2018a, 2018b), Gallucci y Vargas (2015), Fernández (2012) sobre el español hablado en Caracas y Mérida (Venezuela); Grajales Alzate (2017) sobre el español de Medellín (Colombia); San Martín y Guerrero (2013) y San Martín (2015) en el español hablado de la ciudad de Santiago de Chile.

Tras unas aproximaciones previas (Repede 2017, 2018) sobre el empleo del discurso referido en el sociolecto alto y bajo del corpus PRESEEASevilla, el propósito de este trabajo consiste en analizar de forma unitaria las citas en discurso directo e indirecto en todas las muestras de habla de la ciudad hispalense que constituyen este corpus. En concreto, nos proponemos identificar el tipo de marco introductor de discurso referido que aparece en el corpus y la clase de verbos referentes de cita utilizados; describir las funciones pragmáticas del discurso reproducido; clasificar los tipos de cita localizados en los materiales manejados. Y, por último, determinar si el uso del discurso referido en sus dos variantes (DD y DI) está correlacionado con los criterios sociales -edad, sexo y grado de instrucción de los informantes- y estilísticos (el tenor). Asimismo, consideramos que los datos aportados en este trabajo, además, de reflejar el empleo del discurso referido en la ciudad hispalense, pueden ser contrastados con los estudios llevados a cabo en las distintas variedades del español.

\section{Metodología y corpus}

\subsection{El corpus}

Con el fin de realizar esta investigación, hemos seleccionado una muestra de 72 hablantes del Corpus Sociolingüístico de Sevilla 2009-2018 -o PRESEEASE- estratificados en cuotas de afijación uniforme según edad -i) de 20 a 34 años; ii) de 35 a 54; iii) de 55 en adelante-, sexo (el mismo número de hombres y mujeres) y nivel de instrucción. Se ha dividido, así, entre el nivel de instrucción alta (personas con estudios universitarios), nivel de instrucción media (estudios de grado medio y superior, no universitarios), y, por último, hablantes de instrucción baja (sin estudios, con educación primaria y con graduado escolar).

En la Tabla 1 se especifica la repartición de los hablantes de la muestra analizada en este trabajo:

\begin{tabular}{|l|c|c|c|c|c|c|c|}
\hline \multicolumn{1}{|c|}{ Informantes } & \multicolumn{2}{|c|}{ Sociolecto alto } & \multicolumn{2}{c|}{ Sociolecto medio } & \multicolumn{2}{c|}{ Sociolecto bajo } & \multirow{2}{*}{ TOTAL } \\
\cline { 1 - 7 } Edad / Sexo & Hombre & Mujer & Hombre & Mujer & Hombre & Mujer & \\
\hline 20-34 años & 4 & 4 & 4 & 4 & 4 & 4 & 24 \\
\hline 35-54 años & 4 & 4 & 4 & 4 & 4 & 4 & 24 \\
\hline > 55 años & 4 & 4 & 4 & 4 & 4 & 4 & 24 \\
\hline \multirow{2}{*}{ TOTAL } & 12 & 12 & 12 & 12 & 12 & 12 & \multirow{2}{*}{72} \\
\cline { 2 - 6 } & \multicolumn{2}{|c|}{24} & \multicolumn{2}{|c|}{24} & \multicolumn{2}{|c|}{24} & \\
\hline
\end{tabular}

Tabla 1. Distribución de los informantes entrevistados en el corpus oral PRESEEA-Sevilla 


\subsection{Selección de casos}

Para llevar a cabo el presente estudio, nos hemos centrado en el enunciado como elemento de estudio, "es decir, una estructura que puede estar constituida por una o varias oraciones o por alguna unidad menor" (Gallucci y Vargas 2015, 75), como se ilustra en las muestras siguientes:

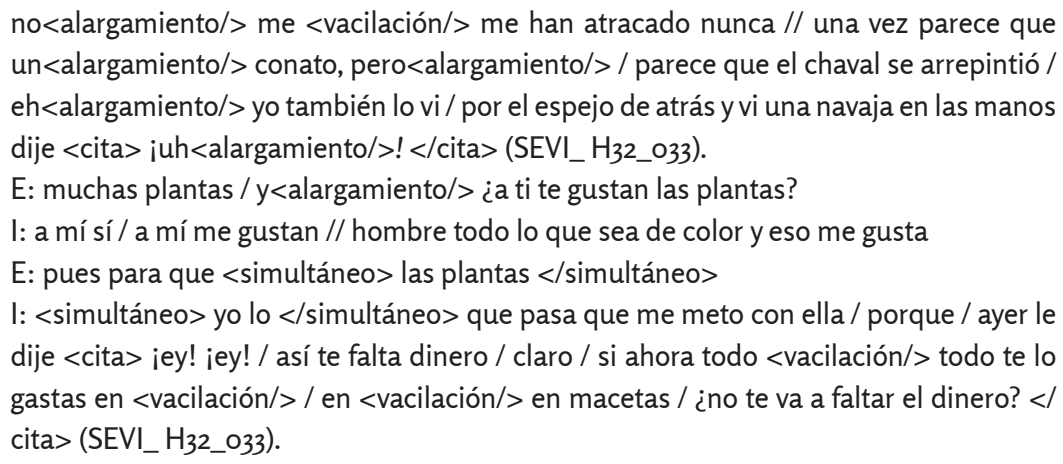

Los ejemplos anteriores de discurso referido parecen cumplir con los requisitos que menciona Maldonado (1999):

que dicho discurso sea la reproducción de una situación de comunicación verbal (y en consecuencia, que la cita vaya introducida por verbos de decir usados de forma descriptiva, no realizativa), y que la situación de enunciación reproductora tenga como objeto la situación de enunciación reproducida (Maldonado, 1999, 3557-3558).

En este caso, en concordancia con los criterios propuestos por la autora, no hemos incluido en nuestro análisis los ejemplos de tipo (6), "cuando los verbos tienen valor realizativo (en presente, en primera persona y cuando no suponen la descripción de una acción sino su realización)" (Galluci y Vargas 2015, 81):

el año pasado por ejemplo mi chica que se cayó / pues me llamaron pues con toda la confianza <cita/ $>$ tranquilízate $<$ cita $/>/$ que $<$ vacilación $/><$ ruido = "chasquido_boca" $/>$ que no te digo que no llamen a cualquier madre / las Ilamarán ¿no? / pero te ves con esa confianza que sabes que <vacilación/> que son amigas ino? (SEVI_M23_067).

Asimismo, se han eliminado los ejemplos cuando el hablante narra un suceso de habla sin mencionar de forma explícita el mensaje transmitido, como en el fragmento (7), ya que se trata de un caso de discurso narrativizado estándar que se presenta como un modo de reproducción de discurso o pensamiento del hablante original, y en el que no puede percibirse ningún tipo de citación o reproducción del texto original (RAE y ASALE 2009):

I: una situación muy difícil / yo tenía el año pasado un alumno / muy / listo inteligente / brillante / pero no le daba la gana / de hacer absolutamente nada

E: uhum

I: hablé con los padres / le mandé una notita / el alumno tuvo la deferencia de entregarla / cosa que no hacen siempre (SEVI_M33_072).

Como se observa, el verbo de comunicación hablar en "hablé con los padres" es el elemento que sintetiza o condensa las palabras referidas (Repede 2017b) ${ }^{3}$. Thompson (1994) denomina este tipo de verbos, reports whithout 
messages, dado que pueden ser utilizados para "refer to language event without giving any information about the message (Aurora didn't answer... complained...)" (1994, 31).

No obstante, como hemos explicado en estudios anteriores (Repede 2017b, 2018b), no se han excluido del análisis secuencias de tipo "y<alargamiento/> me vine / y aquí ya me contó Miguel Ángel el enorme riesgo que es un<alargamiento/> mosquito de esos (SEVI_H33_058) ${ }^{4}$ ", pues el verbo contar introduce un discurso ajeno que se presenta como una reformulación total del contenido de las palabras reproducidas, y donde el que refiere alude de manera expresa a un acto comunicativo de otro, llevado a cabo en una situación de enunciación diferente a la que se está realizando (Repede 2017b) ${ }^{5}$.

Por último, se han descartado también los casos que se reflejan en los siguientes ejemplos:

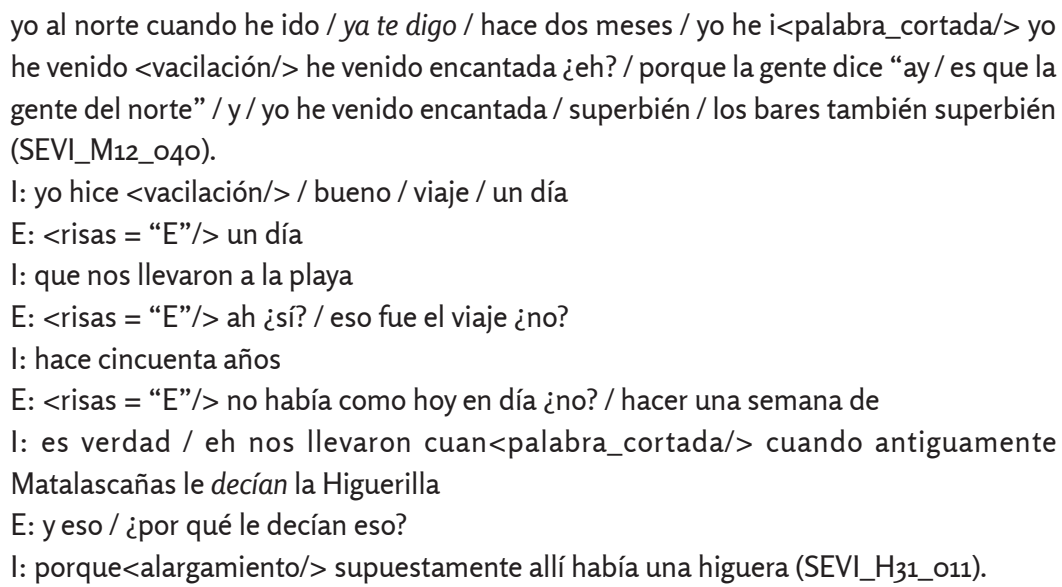

En concreto, se trata de muestras en las que el verbo de habla actúa como un marcador discurso, como en (8), o cuando está acompañado de un complemento predicativo, según el (9), ya que se utiliza con el significado de llamar o apodar.

\subsection{Procedimiento de análisis}

Basándonos en estudios anteriores (Repede 2017b, 2018b; Gallucci y Vargas 2015; Fernández 2012) y para poder realizar estudios contrastados con otras comunidades de habla hispana, hemos considerado como variable dependiente el discurso referido con sus variantes (DD y DI). Asimismo, con el fin de llevar a cabo el análisis, se han tenido en cuenta distintos criterios lingüísticos (marco introductor de cita; tipo de verbo referente de cita; duplicación de discurso referido, presencia/ausencia del nexo que) y pragmáticos (atribución de la cita; función del discurso referido).

Con respecto a los factores lingüísticos, nos hemos centrado, en primer lugar, en el marco introductor de discurso que se desglosa en: i) canónico y ii) no canónico. El marco canónico recoge los casos de discurso referido introducido mediante un verbo conjugado o no, como en el fragmento (10):
4. En este tipo de ejemplos no aparece el nexo que y la subordinada del discurso indirecto estándar corresponde a un sintagma nominal.

5. Cabe mencionar aquí que también se han considerado en este análisis los escasísimos ejemplos en los que el verbo de comunicación introduce un refrán. En el ejemplo siguiente, el hablante refiere las palabras de una voz anónima para describir determinadas formas de conducta:

y luego nos llevaba por la mañana y los cacharritos te montabas / y claro a lo mejor pagaba una de eso y nos llevábamos dos horas en los cacharritos porque claro / viendo el tío que estaba la gente montada / acude la gente / dice <cita > ¿dónde vas Vicente? donde van la gente $</$ cita $>$ $<$ risas = "E"/> (SEVI_M32_045). 
E: uhum

I: ¿vale? / tenía aquí un grano y le digo <cita> ostras / illo Juan Ramón / vaya granaco ¿no?

$</$ cita> (SEVI_M12_039).

En cambio, dentro del marco no canónico se han incluido los casos de discurso referido en los que aparecen sin verbo introductor (11):

I: que la verdad que llevamos un mes separados de ellos / lo reconozco / me he separado teniendo novia

E: ya

I: pero no he perdido el contacto / me llaman para jugar al fútbol / <cita> bueno vámonos a mí no me importa / voy a jugar al fútbol con ustedes </cita> / pues algún día quedamos (SEVI_H21_027).

o introducidos mediante:

un marcador discursivo (12):

entonces cuando llegó a Castilleja se enteraron de que era el novio pues < cita> chiquillo tú no puedes estar aquí <risas = "E”/> tú no puedes ver el traje de la novia / ¿tú qué haces aquí? </cita> (SEVI_M22_044).

un sintagma nominal precedido o no por la conjunción y $(13 ; 14)$ :

que bailé / en la parte de atrás donde nadie < vacilación/> nadie < vacilación/> que la bailé con $u<$ palabra_cortada/ $>$ una de mis mejores amigas $/<$ risas = "todos" $/>$ y todo el mundo <cita $>$ ibaila baila! </cita > y yo <cita $>$ que no bailo < risas = "todos"/> que no bailo / que me dejéis en paz con el baile ¡leche! </cita> / y bailé una sevillana allí escondida en un rinconcito $<$ risas = "todos"/ $>$ (SEVI_M22_041).

I: ¿cúantos fe<palabra_cortada/> días de feria hay? cuatro / cinco / pues yo voy uno o dos

E: uhum

I: pero que ya está / yo voy a eso / a estar un ratito allí / a echar un par de monedas de euro en la moned<palabra_cortada/> en la máquina de las pincitas

E: uhum

I: y me voy

E: uhum

I: que no estoy allí para estar<alargamiento/> para estar todo el día

E: uhum uhum

I: <ruido = "chasquido_boca"/> que yo sé cómo es aquello / todo el mundo <cita > iah! vamos a beber irebujito / rebujito! </cita> al final se pone uno como se pone y al final se lía allí / tú estás metido en el medio (SEVI_H23_027).

la conjunción y (15):

en la facultad no / te tienes que buscar tú los apuntes / copiar<alargamiento/> apuntes / o te dan < vacilación/> o te dicen un libro y <cita> ¡venga! a buscar información en este libro </cita> / te tienes que buscar un poco más la vida / digamos / en la facultad (SEVI_M12_037).

También se han recogido aquí las diferentes estructuras nominales seguidas de la preposición de (16) que pueden introducir discurso referido:

pero / también / que sea por un problema que tú estés tan gordo que tu salud <ininteligible/> tu salud le perjudica / entonces me parece bien hacer dieta // pero si tú comes bien y haces deporte $<$ alargamiento/ $>0$ andas $0<$ alargamiento/ $>0$ estás bien / o te sientes 
bien contigo mismo // no tiene < vacilación/> lo que pasa es que si hay mucha presión social de <cita/> iay / que gorda estás! / ¡no estoy en el pantalón! / ¡ay / en esa tienda no me puedo comprar! / iay / pues no tengo dinero! <cita/> (SEVI_M23_065).

En segundo lugar, se han considerado los tipos de verbos que refieren las palabras propias y/o ajenas. Se analizan únicamente aquellas secuencias en las que aparecen un verbo como introductor de discurso referido. Así, este factor presenta dos parámetros: i) el verbo decir (17); ii) otros verbos como referentes de discurso reproducido (18):

\begin{abstract}
tenía quince años / <risas = "E"/> y fui sola a la hermandad / y dije <cita $>$ mira que yo me quiero hacer hermana / que yo quiero salir de nazareno </cita> / entonces me dijeron $<$ cita> bueno pues tráeme la partida de bautismo </cita> / y es que me bauticé aquí / se la pedí allí / le rellené el papel / se lo dije a mi madre / y yo fui y me hice hermana <risas = “E”/> / y desde entonces / salgo todos los años / desde el año dos mil (SEVI_M12_040). además / la vida te va llevando por caminos muy distintos // ya sea por trabajo / ya sea por<alargamiento/> circunstancias / por propia vagueza / porque nos cuesta mucho trabajo coger un teléfono y llamar y preguntar <cita> ¿ioye cómo estás? </cita> / eso nos cuesta trabajo a todos (SEVI_M22_041).
\end{abstract}

También hemos tomado en consideración el criterio sintáctico duplicación del discurso reproducido con tres variantes. Las dos primeras se emplean para codificar las formas en que se produce la duplicación del discurso referido: catafórica, en el ejemplo (19) y anafórica, según el fragmento (20):

I: y en la Trinidad / ellos son muy

E: puntuales ¿no?

I: sí // son muy estrictos // además siempre te lo dicen / cuando vas a <vacilación/> a apuntarte y demás / te dicen que si no eres puntual no te casas (SEVI_M22_044).

pero como vino el de ese <ruido = "golpe en la mesa"/> y le dijo que me hablara en castellano / vamos qué coño / digo < vacilación/> digo ya < vacilación/> ya me puse así $<$ cita> yo / yo no tengo nada que ver con los catalanes ni nada / zyo voy a hablar catalán ni yo me < vacilación/> me voy a venir acá $a<$ vacilación/> a Barcelona? $</$ cita $><$ risas = "E"/> $/ /$ hombre es que yo eso lo veo de muy poca vergüenza (SEVI_M32_045) ${ }^{6}$.

Respecto a la tercera variante, remite a los casos en los que no hay repetición de discurso:

y<alargamiento/> fui allí a <alargamiento/> a verla / y me sorprendió digo <cita > la de cosas que tiene Génova </cita> / digo <cita> mmm ¡Dios mío / lo bonita que es! </cita> (SEVI_M32_048).

El criterio sintáctico presencia/ausencia de la conjunción que se desglosa en dos parámetros. El primero se refiere a los casos en los que el discurso referido (tanto el directo como el indirecto) aparece con el nexo que:

porque la bar<palabra_cortada/> la zodia es bastante grande / cuando ya me amarran yo con mi dedo en el <vacilación/> en una bolsita con hielo / con mi chaquetón <risas = "E"/>/y cuando yo<alargamiento/> miro para <alargamiento/ la mar / yo decía que <cita> Dios mío Dios mío Dios mío / a dónde coño me van a meter esta gente </cita> / porque ha<palabra_cortada/> / Doina / hacía muy mala mar (SEVI_H22_031).

El segundo incluye las muestras en las que en el discurso referido no se utiliza el que:
6. El discurso reproducido no siempre es complemento directo, sino que puede desempeñar el papel sintáctico de complemento circunstancial. En este caso, es posible la duplicación del discurso referido mediante un adverbio. Para más detalles, Repede (2015a; 2015b). 
una vez que me jubile / todavía me quedan unos años / pero <risas = "l"/> / yo no lo espero cuando me jubile / lo espero cada día / porque creo que la vida hay que vivirla cada día / entonces cuando a mí me dicen <cita> pero tú ¿por qué no descansas? por la tarde / estás tranquilo </cita> pues porque para mí / parte de la vida es moverme / y necesito moverme (SEVI_H33_057).

En cuanto a los criterios pragmáticos, hemos tomado en consideración tipo de atribución de la cita y función de la cita. El primer factor sirve para "conocer a quién(es) los hablantes le atribuyen la palabra citada, pues esto refleja en qué medida se comprometen con lo que dicen" (Gallucci y Vargas $2015,88)$. Presenta cuatro formas diferentes ${ }^{7}$ :

i) cita propia. El hablante reproduce sus propias palabras expresadas en otro momento del discurso y muestra más compromiso e implicación en lo que dice:

antes no porque yo he vivido siempre en pisos / pero desde que vivo en la casa / cuando voy a una barriada de estas de cuarenta mil bloques / digo <cita> no sé cómo se puede vivir aquí / vamos </cita> (SEVI_M22_042).

ii) cita ajena. El sujeto refiere la palabra de otro y se distancia más discursivamente:

porque yo me acuerdo / que yo antes se lo decía / yo los miércoles daba Urbanidades y dice mi hija <cita> ¿eso qué es? </cita> / digo <cita> nosotros lo dábamos </cita> / digo <cita $>$ pues eso es el comportamiento de las personas </cita> (SEVI_M32_045).

iii) cita impersonal. El discurso que se refiere no remite directamente al propio hablante o a un referente ajeno, sino que presenta un uso impersonal. Mediante el empleo de este tipo de cita, el hablante intenta ocultar su identidad, en busca de acuerdo o aceptación social, o convencer al receptor de la validez de lo expresado, como en (26):

I: la Feria es otra cosa <risas = "E"/> / la Feria es alegría por todos lados / a todos lados que vas / y<alargamiento/> estar pasándolo bien con amigos<alargamiento/> siempre / mmm vas un día / dices <cita > mañana no voy </cita > y vuelves a ir / y vuelves a ir y $<$ vacilación/> y cuando llega el momento dices <cita> si he ido todos los días </cita> / normal / es una cosa que te llama la atención / que tienes que ir / que nada más que vas entrando estás sintiendo ya / la Feria (SEVI_H12_025).

iv) cita encubierta. El hablante minimiza su responsabilidad sobre lo dicho e indica que la información procede de terceros. En el ejemplo (27), el informante no asume el contenido de lo que afirma, sino que está repitiendo las palabras de otros ${ }^{8}$ :

<simultáneo> en todo el mundo </simultáneo> / el tema de los ciclones / de<alargamiento/> las inundaciones y demás no es solo aquí / es en todo el mundo pero < vacilación/> / claro / algo habrá de razón / pero vamos / también dicen que es el cambio del<alargamiento/> del tiempo / que son ciclos / las mareas / la <vacilación/> / el deshielo / que todo influye un poco vamos (SEVI_H22_029).

Tal como se ha confirmado en otros estudios (Gallucci 2009, Fernández 2012 , entre otros), "la cita puede tener cuatro funciones distintas, dependiendo de cuál sea la intención del hablante que emplea este recurso y de la secuencia discursiva de la que forma parte" (Gallucci y Vargas 2015, 89):
7. La explicación de cada uno de los tipos de cita está tomada de Repede (2018b).
8. Si bien es verdad que los últimos dos tipos de cita presentan en el discurso un uso impersonal, en la cita encubierta, se trata más bien de una despersonalización del centro deíctico del enunciado. 
i) relatar anécdotas y/o hablar de experiencias propias o ajenas; ii) ejemplificar ${ }^{9}$; iii) expresar opiniones o creencias ${ }^{10}$; iv) argumentar. Los fragmentos siguientes ilustran cada una de las secuencias mencionadas:

y entonces la criatura se agacha de pronto y no lleva nada puesto debajo y me enseña el pompis $\mathrm{E}$ : ¿en serio? <risas = "E"/>

I: en serio / y dice <cita> jay! ¿se me ve todo verdad hija? </cita> / y digo <cita> iay! / yo no me he dado cuenta de nada hijo </cita> (SEVI_M21_018).

por ejemplo una chica me dijo la semana pasada <cita/> pues yo estuve ya con<alargamiento/> diez años con una psicóloga y nunca me hizo nada / y esto me está haciendo mucho más de lo que yo esperaba <cita/> (SEVI_M13_062).

la primera lo vi de blanco digo <cita $>$ o me he equivocado del barrio / o esto no / a mí <vacilación/> aquí ha pasado un expediente $X</$ cita $><$ risas = "E"/> / pero< <alargamiento/> no sí / y ya por ejemplo / han limpiado mucho lo que es la zona de<alargamiento/> así de gentilla que había en<alargamiento/> / había muchos yonkis por allí(SEVI_M22_041). pues $<$ alargamiento/> pienso que $\mathrm{mmm}$ todo<alargamiento/ $>$ todo el mundo es<alargamiento/> libre<alargamiento/> a elegir // cómo quiere estar y cómo quiere vivir // y yo<alargamiento/> si estuviera<alargamiento/> tuviera que estar en una máquina como un vegetal / enchufado / a mí me dicen que<alargamiento/> <cita > mira / que vas a vivir // hasta que te mueras de muerte natural / pero vas a estar de esta forma / así enchufado / mmm mal / no vas a poder andar / no vas a poder hacer // muchísimas cosas / en una camilla </cita> / pues hombre / hay gente que eso lo aguanta (SEVI_M12_037).

Para los criterios extralingüísticos, como ya se ha mencionado previamente, se han considerado tres parámetros: edad, sexo y nivel de instrucción. Asimismo, nos hemos centrado en el condicionante estilístico tenor, esto es, participantes conocidos o desconocidos previamente en la interacción.

En cuanto al procesamiento y presentación de los datos manejados en este estudio, nos basamos en la estadística descriptiva, esto es, el cómputo de frecuencias absolutas y relativas. Asimismo, con el fin de ver qué criterios han resultado significativos en nuestro estudio, empleamos la prueba del ji cuadrado $\left(\chi^{2}\right)$ y el valor de $p(<0,05)$. No obstante, cuando se han encontrado casillas con menos de cinco casos, se ha calculado también el valor de $p$ según la prueba exacta de Fisher.

\section{Estudio y resultados del discurso referido en el corpus oral PRESEEA-Se}

En las 72 entrevistas semidirigidas que forman parte del corpus PRESEEA en la ciudad de Sevilla, se han localizado 1420 secuencias de discurso reproducido. En la tabla 2 se presentan las frecuencias de empleo de las dos variantes dependientes del discurso referido registradas en los materiales manejados:

\begin{tabular}{|l|c|c|}
\hline Discurso referido & $\mathbf{N}$ & $\mathbf{\%}$ \\
\hline DD & 1010 & 71,13 \\
\hline DI & 410 & 28,87 \\
\hline TOTAL & 1420 & 100 \\
\hline \multicolumn{2}{|l|}{ Tabla 2. Distribución de DD y DI en el corpus PRESEEA-Sevilla }
\end{tabular}

Se deja ver, así, la preferencia de los hablantes sevillanos por el DD, ya que 1010 casos $(71,13 \%)$ corresponden al DD y 410 ocurrencias son de DI, que constituyen un 28,87\%.
9. Como no podemos establecer límites claros entre la secuencia de relatar y ejemplificar, ya que, en general, llegan a superponerse, se debe entender por función de ejemplificar cuando "una cita forma parte de una secuencia narrativa y sirve para ilustrar una circunstancia" (Gallucci y Vargas 2015, 80). 10. Expresar opiniones o creencias es también un modo de argumentar. No obstante, hemos delimitado esta secuencia cuando predomina la intención del hablante de manifestar sus pensamientos por encima del deseo de persuadir de algo al receptor. 


\subsection{Discurso referido y criterios sintácticos}

Con respecto a los criterios sintácticos considerados en este análisis (marco introductor de discurso, tipo de verbo referente, duplicación de discurso referido, presencia/ausencia del nexo que ${ }^{11}$ ), presentamos aquí solo los que han dado resultados significativos, esto es, marco introductor de discurso y tipo de verbo introductor de cita.

En primer lugar, como ya se ha mencionado previamente, el marco introductor de discurso referido puede presentar dos formas diferentes: canónico, es decir, a través de un verbo, conjugado o no; y no canónico, esto es, sin verbo, marcador discursivo, sintagma nominal, nexo y o estructuras nominales precedidas de la preposición de. Por tanto, del total de formas de discurso reproducido $(\mathrm{N}=1420)$ localizadas en el corpus manejado, 1229 muestras (86,55\%) presentan un marco canónico, donde 819 ejemplos pertenecen al DD y 410 casos al DI:

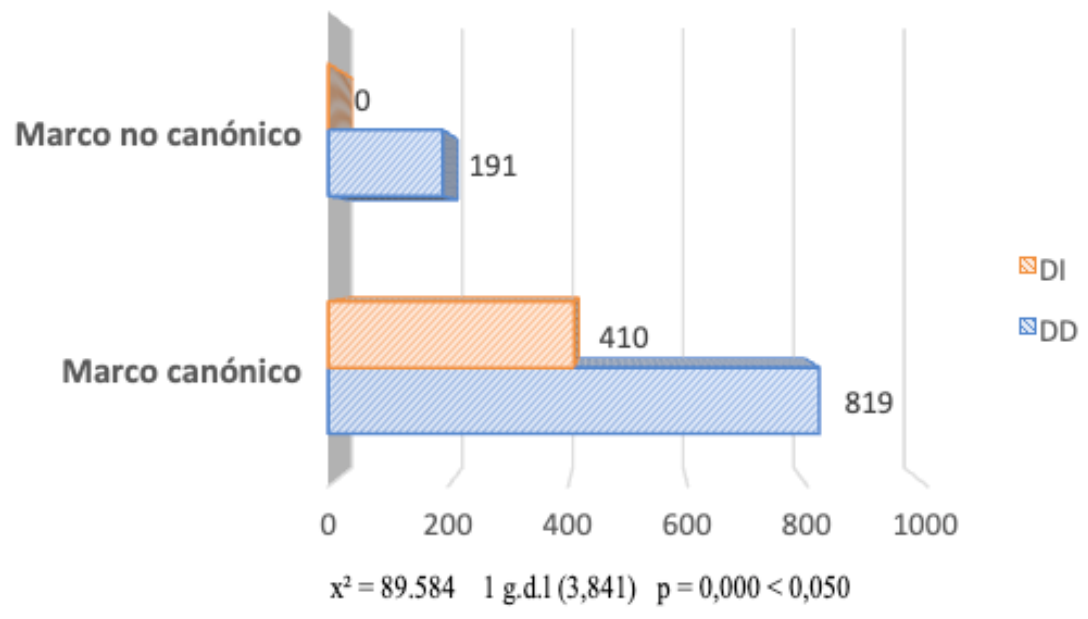

Gráfico 1. Discurso referido y marco introductor ${ }^{12}$

11. Los criterios duplicación de discurso referido y presencia/ausencia del nexo que han resultado significativos en otros estudios sobre este procedimiento citativo (Repede 2017b, 2018b).

Para el marco no canónico, se han documentado 191 casos, todos de DD, lo que supone un $13,45 \%$. Si nos centramos únicamente en este último tipo de mecanismo, podemos apreciar en el gráfico 2 las distintas posibilidades de los hablantes para introducir la cita en estilo directo.

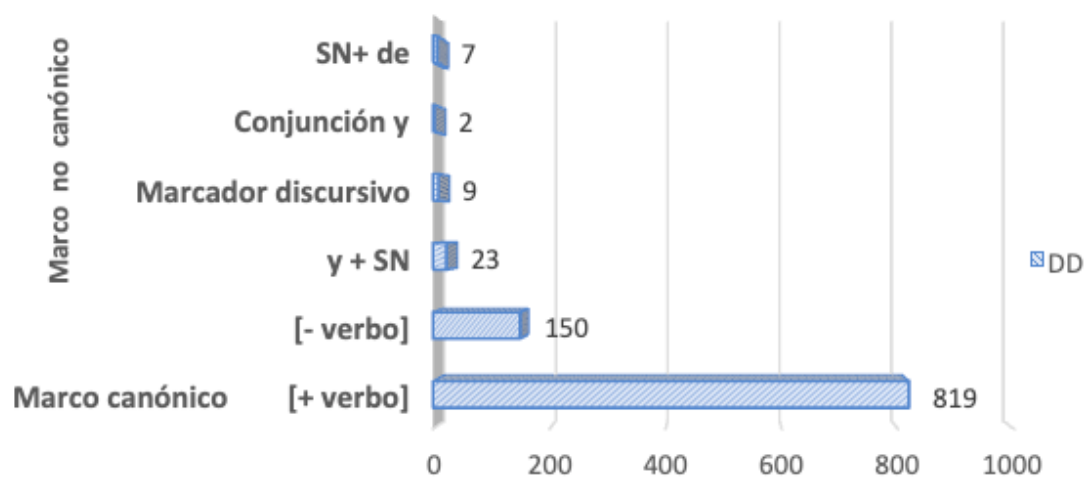

Gráfico 2. DD y marco introductor

12. Según la prueba exacta de Fisher, el valor de $p$ es igual a o,oo. 
Se han registrado, en este caso, 819 secuencias introducidas por un verbo $^{13}$, lo que se traduce en un $82,72 \%$ del total $(\mathrm{N}=1010)$. No obstante, de acuerdo con los datos presentados en el gráfico 2 , el verbo introductor representa una de las posibilidades con las que cuentan los sujetos hablantes para reproducir el discurso en forma directa. Todo ello pone de manifiesto que, en contra de lo que afirma Maldonado (1999, 3554), no siempre es necesario un verbo de decir conjugado para referir una cita en discurso directo.

Por tanto, el marco no canónico más utilizado es [-verbo] con 150 ocurrencias, es decir, 14,85\%. Menos incidencia tienen las otras opciones para introducir la cita directa. En este caso, se han documentado 23 secuencias de DD introducidas por la estructura $(y)+S N$, esto es, $2,28 \%$. Si se trata de un marcador discursivo como introductor de DD, hemos encontrado 9 casos $(0,89 \%)$. En cuanto al nexo y como introductor de discurso, se han recogido tan solo 2 muestras $(0,20 \%)$. Y, por último, hemos registrado 7 ejemplos de $S N+d e$, los supone apenas un 0,69\%.

En cuanto a la clase semántica de verbos introductores de cita, Gallucci (2009, 2013, etc.) indica que los dos tipos de discurso objeto de nuestro interés pueden ser introducidos por verbos como decir, preguntar, sugerir, aconsejar, entre otros. En el gráfico 3 presentamos, de los 1239 casos de la muestra introducidos por un verbo, la proporción entre el verbo decir y los otros verbos que hemos encontrado en las secuencias de discurso referido estudiadas:

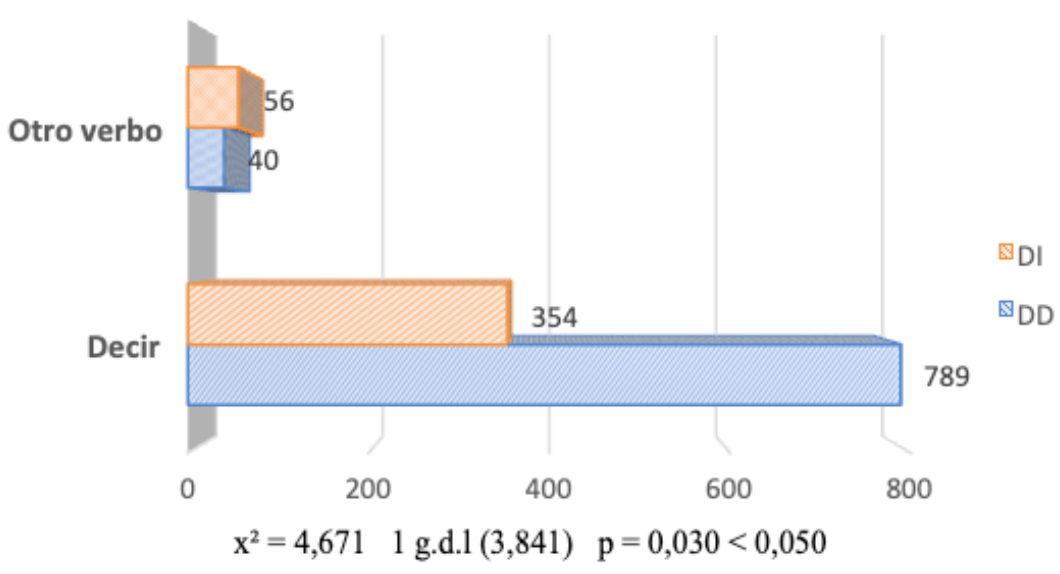

Gráfico 3. Discurso reproducido y tipo de verbo introductor

En el corpus PRESEEA-SE el verbo más empleado para reproducir tanto en DD como en DI es decir, con un total de 1143 casos (92,25\%), donde 789 ejemplos pertenecen al DD y 354 al DI. La amplia aparición de este verbo en el corpus manejado puede estar relacionada con su carácter neutro desde el punto de vista semántico, cuya "presencia implica una información mínima sobre las circunstancias que rodean el acto de habla" (Repede 2017a, 23). Al mismo tiempo, esta neutralidad del verbo decir le concede no solo cierta invisibilidad, sino también la capacidad de repetirse en un texto, sin que esto resulte molesto para el lector (Poncharal 2006; Volsik 1993) o, en nuestro caso, el interlocutor.
13. Estudios previos como los Gallucci (2009, 2013) sobre el español caraqueño y el de Fernández (2012) sobre el español de Mérida (Venezuela) también muestran que el verbo es el marco introductor de discurso referido preferente de los informantes encuestados para introducir las citas. 
Además de este verbo, que como hemos visto, es el menos marcado, ya que simplemente indica una aserción, se han localizado 96 ejemplos introducidos por otros verbos diferentes del verbo decir, lo que se traduce en un 7,75\%. En este caso, 40 aparecen con DD y 56 introducen DI.

En el siguiente gráfico se detallan los verbos más empleados en nuestro corpus:

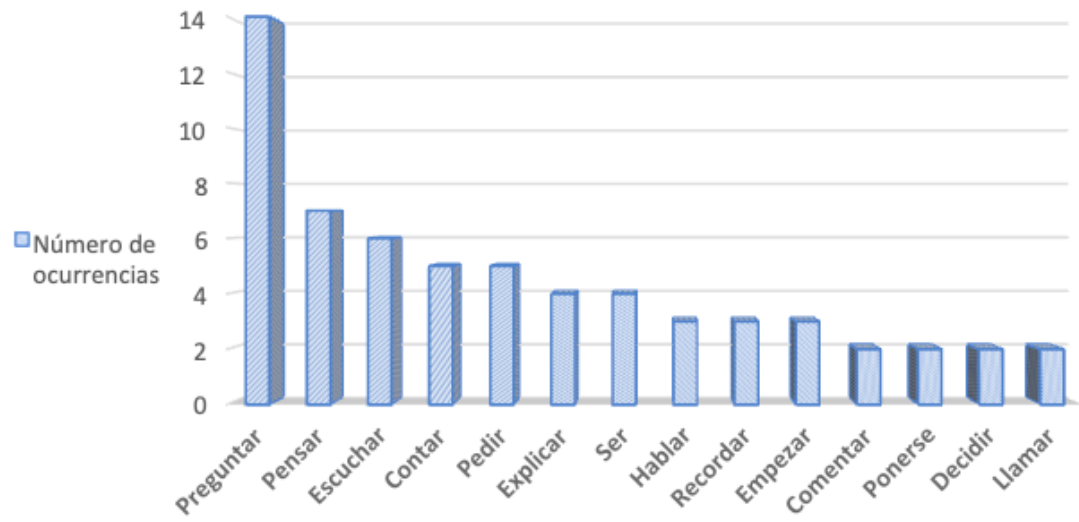

Gráfico 4. Distribución des verbos introductores de discurso reproducido

A estos le siguen, solo con un caso, otros verbos de comunicación como advertir, confesar, contestar, enseñar, proponer, repetir, saludar, subrayar; de sugerencia (recomendar) o de promesa (prometer), etc.

De los verbos presentados en el gráfico 4, preguntar, hablar, contar, comentar son los menos marcados, ya que indican una aserción y se centran "en el contenido del mensaje del hablante, sin aportar ningún matiz" (Repede 2018a, 102). No obstante, parece que los hablantes tratan de implicarse más con lo que refieren a través de otros verbos. Así, pedir es un verbo de petición que "describe ilocutivamente el discurso referido: se trata de un acto directivo, de tipo apelativo" (ibídem, 287). Recordar "implica que el emisor de las declaraciones insiste en algo que haya dicho en alguna otra ocasión [...]. Indica la validez, provisionalmente o no, de un discurso anterior válido" (ibídem, 332).

tengo que llevar tortilla de patatas / hace dos años me negué / digo / <cita > no hago tortilla de patatas $</$ cita $><$ risas = "todos"/ $>/$ digo $<$ cita $>$ yo puedo hacer otra cosa / o comprar / me libero de hacer tortilla de patatas para todo el mundo </cita / entonces le<alargamiento/> pas<palabra_cortada/ > le dije a mi sobrina digo <cita $>$ a ti te toca este año aprender a hacer la tortilla de patatas / <risas = "E"/> / que me vas a sustituir $</$ cita> / a mí solo me van a recordar <cita > ay en Navidades / ay lo que echamos de menos la tortilla de patatas de la tita $E</ c i t a>$ / a la tita $E$ no la recordarán en nada <risas = "todos"/> pero la tortilla / porque eso es la parte / de todas las generaciones (SEVI_M32_048).

Explicar presenta "un valor retrospectivo con la intención de hacer más claro y comprensible el discurso referido; presupone la existencia de hechos confusos o imprecisos" (Repede 2018a, 209). Decidir "interpreta el acto de habla ajeno indicando la actitud que tiene el hablante, proporcionando más fuerza a la aserción originaria" (ibídem, 141). Y, mediante el verbo escuchar, "el hablante reproduce un discurso especificando el modo de acceso al conocimiento" (Gallucci 2018b, 320). 


\subsection{Discurso referido y criterios pragmáticos}

Como se ha explicado previamente, hemos considerado el tipo de cita que cuenta con cuatro parámetros: cita propia, cita ajena, cita impersonal y cita encubierta. En el gráfico 5 presentamos la distribución del tipo de cita en los materiales empleados para este estudio:

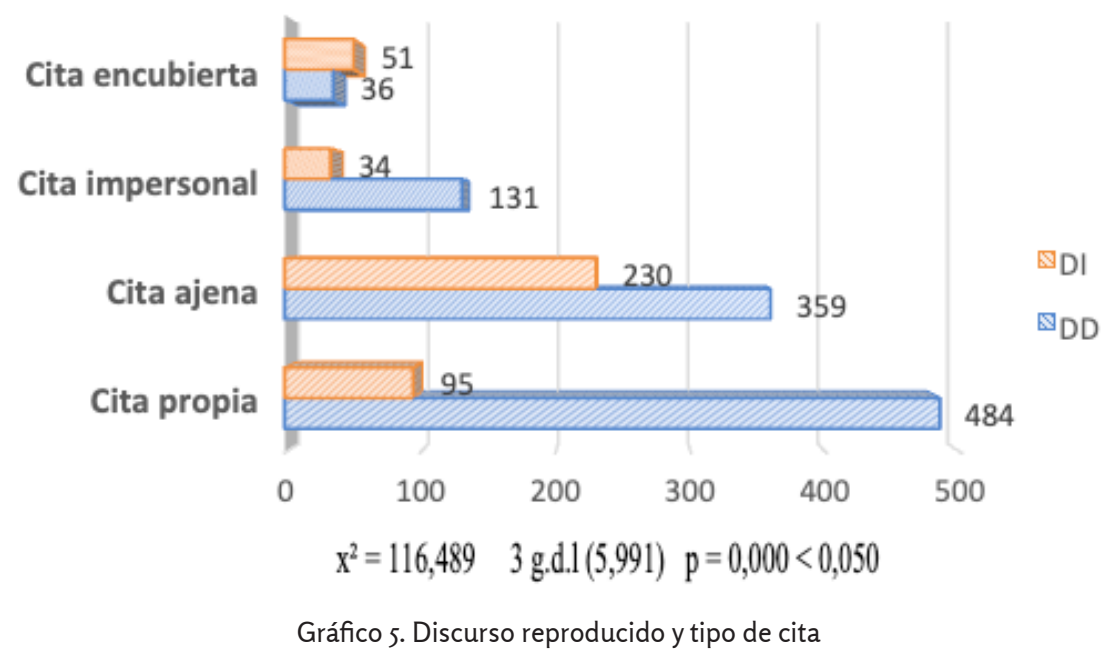

Es posible observar la preferencia de los hablantes de la muestra por la reproducción de palabras propias. Así, del total de 1420 de casos estudiados, la cita propia se localiza en 579 ejemplos $(40,77 \%)$ y la cita ajena se encuentra en 589 secuencias $(41,48 \%)$. En cuanto a las últimas dos variantes, se han documentado 165 ocurrencias $(11,62 \%)$ para la cita impersonal y 87 muestras $(6,13 \%)$ para la cita encubierta. Estos resultados permiten concluir que, al menos en la muestra analizada, en líneas generales, es más frecuente la cita ajena, seguida de la cita propia. Si bien podemos observar que la diferencia entre los dos tipos es 0,71 puntos porcentuales.

Sin embargo, el DD predomina en todos los tipos de cita, excepto en la cita encubierta. En otras palabras, en la cita propia $(\mathrm{N}=579)$ notamos que el DD muestra una inclinación bastante alta hacia la reproducción de palabras propias $(83,59)$ en detrimento del DI $(16,41 \%)$. Para el segundo tipo de cita $(\mathrm{N}=589)$, el DD se utiliza un $60,95 \%$ y el DI un $39,05 \%$. Cuando se trata de la cita impersonal, el DD aparece un 79,39\% a diferencia del 20,61\% del DI. En cuanto a la cita encubierta, observamos que es el DI el que se emplea más, esto es, un 58,62\%, y el DD aparece un $41,38 \%$.

Además de la función general del discurso referido -esto es, relatar (una anécdota, experiencias personales o ajenas)-, mediante el uso de la cita el hablante puede ejemplificar, argumentar o expresar pensamientos y/o creencias. El gráfico 7 ofrece los resultados que se han obtenido en este aspecto: 


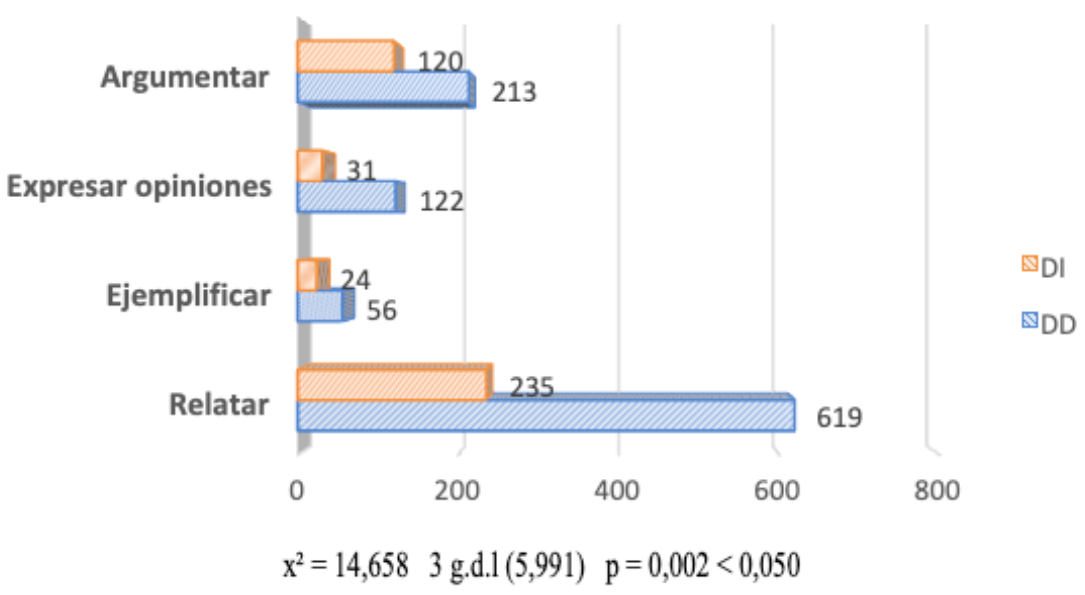

Gráfico 6. Discurso reproducido y secuencia discursiva

Observamos, así, que tanto el DD como el DI se registran mayoritariamente en las secuencias discursivas de tipo narrativo, aunque con una evidente predominancia del DD. En concreto, la función más frecuente es la de relatar anécdotas o experiencias con 854 casos (60,14\%) de los 1420 de la muestra utilizada para este estudio. Le sigue, en orden descendente, la función de argumentar, correspondiente a 333 ejemplos (23,45\%), manifestar un pensamiento, con 153 ocurrencias (10,77\%), y, por último, la circunstancia de ejemplificar, con 80 casos (5,63\%). Si desglosamos por tipo de discurso, el DD se emplea en todas las funciones de la cita mencionadas: relatar con 619 casos $(61,28 \%)$, ejemplificar con 56 ejemplos $(5,54 \%)$, expresar un pensamiento con 122 ocurrencias $(12,08 \%)$ y argumentar con 213 casos $(21,09 \%)$. Por lo que se refiere al comportamiento del DI, se ha manifestado en las secuencias narrativas con 235 ocurrencias (57,32\%), en las argumentativas con 120 casos $(29,27 \%)$, y, en menor proporción, en la función de ejemplificar con 24 muestras (5,85\%), y en la de expresar pensamientos y opiniones, donde se han localizado tan solo 31 secuencias $(7,56 \%)$.

Al realizar un cruce de factores entre el tipo de cita y la función pragmática de esta en el contexto para mayor definitud, observamos, de acuerdo con los datos ofrecidos en el gráfico 7, que la cita ajena y la cita propia se relacionan con la función de narrar y, en menor medida, con las otras funciones pragmáticas.

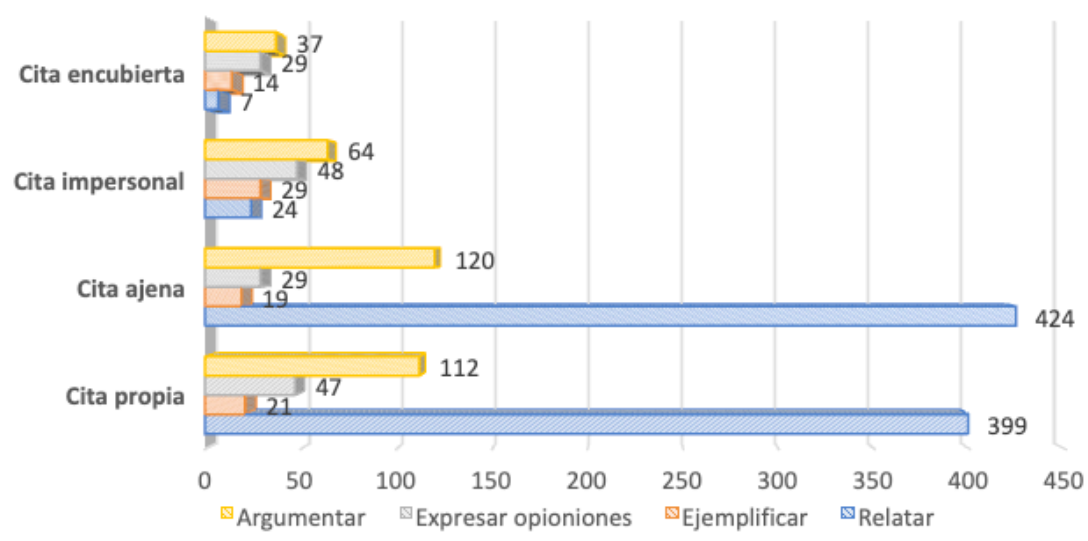

Gráfico 7. Tipo de cita según la secuencia discursiva 
Con respecto al primer tipo de cita, del total $(\mathrm{N}=579)$ de ocurrencias, esta se utiliza para relatar un 68,91\%, para expresar sus opiniones o creencias un $8,12 \%$ y para argumentar un $19,34 \%$. En cambio, menos incidencia tiene la secuencia de ejemplificar, que se emplea solo un 3,63\%. La cita ajena presenta la siguiente distribución: 71,99\% para hablar de experiencias personales, $20,37 \%$ para argumentar y $4,92 \%$ cuando los hablantes manifiestan sus pensamientos o creencias. El 3,23\% restante corresponde a la secuencia de ejemplificar.

Sin embargo, según el gráfico 7, parece manifestarse la tendencia contraria con respecto a los dos últimos tipos de cita. Así, de las 165 ocurrencias de cita impersonal localizadas en la muestra, el 38,79\% se utiliza para argumentar. A esta última le siguen en orden decreciente, los casos de expresar opiniones (29,09\%), ejemplificar $(17,58 \%)$ y relatar $(14,54 \%)$. Si nos centramos en la cita encubierta $(\mathrm{N}=87)$, podemos observar también un porcentaje bastante alto $(52,52 \%)$ correspondiente a la función argumentativa. Con respecto a las demás funciones, se ha registrado un 33,33\% de cita encubierta para expresar opiniones y un 16,09\% para ejemplificar. Por último, para la secuencia narrativa, encontramos un $8,04 \%$ de este tipo de cita.

\subsection{Discurso referido y criterios extralingüísticos}

Con relación a los criterios extralingüísticos, hemos tenido en cuenta tres factores sociales (edad, sexo y nivel de instrucción) y uno estilístico (tenor). Relativo al sexo de los informantes encuestados, el gráfico 8 muestra los resultados obtenidos según los dos tipos de uso contemplados en este análisis:

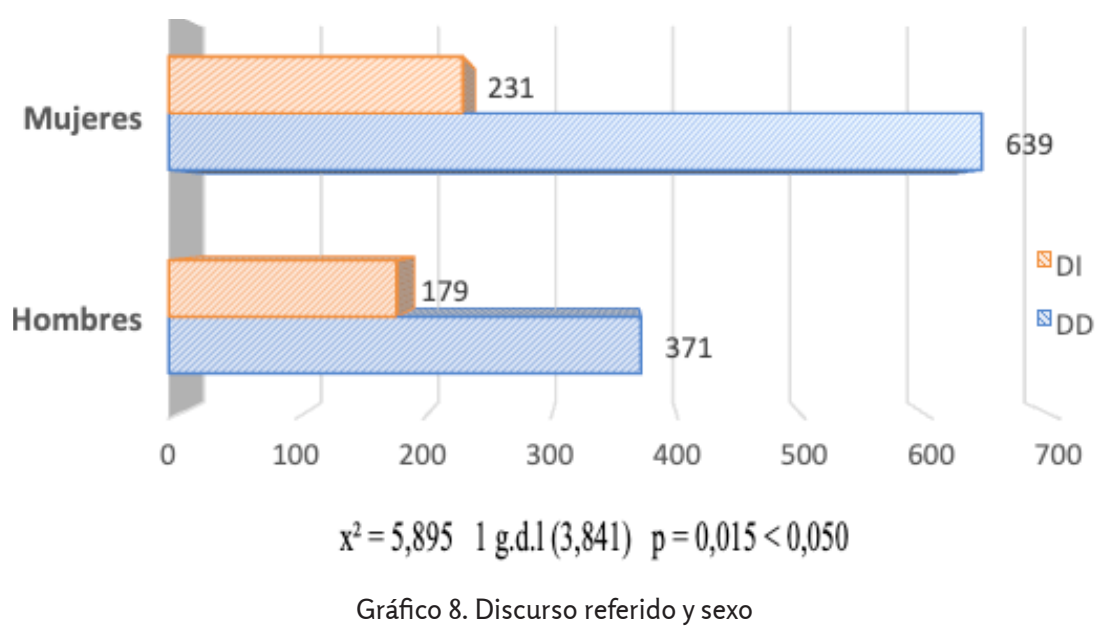

En primer lugar, notamos que el DD, tanto en hombres como en mujeres, muestra una amplia aparición en comparación con los casos en los que se registra el DI en ambos sexos. En segundo lugar, constatamos que el empleo del discurso referido en las encuestas se manifiesta mayoritariamente en las mujeres. En otras palabras, de las 1420 secuencias de discurso reproducido, 870 ejemplos $(61,27 \%)$ pertenecen a las mujeres (639 de DD y 231 de DI). En cuanto a los hombres se han registrado 550 secuencias de discurso referido (38,73\%), donde 371 pertenecen al DD y 179 al DI.

En el gráfico 9 ilustramos los resultados obtenidos de acuerdo con el factor edad: 


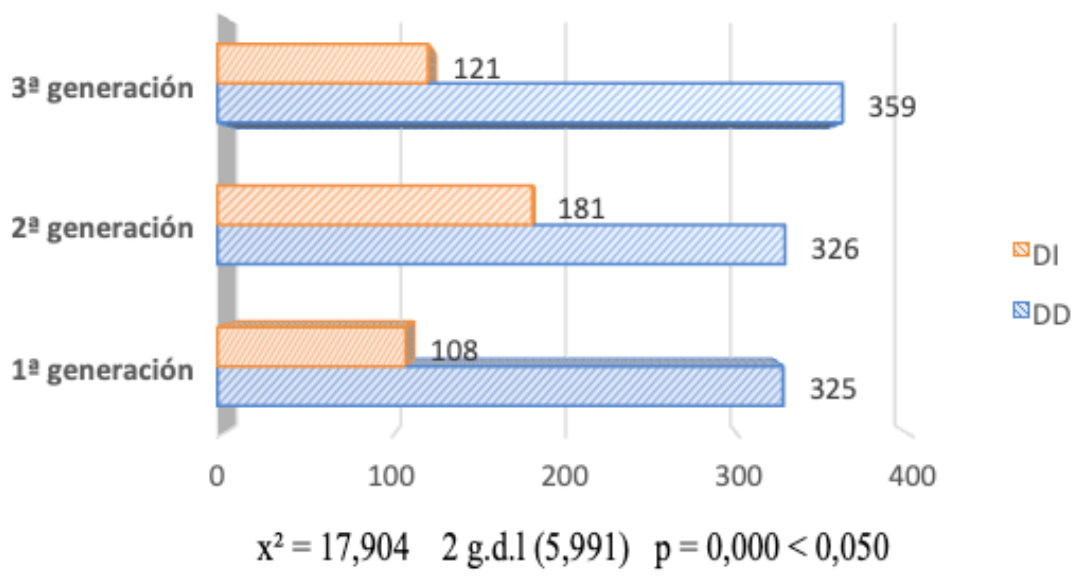

Gráfico 9. Discurso referido y grupo generacional

De las 1420 ocurrencias de discurso reproducido localizadas en nuestro corpus, es el segundo grupo generacional el que más uso de este recurso hace, con 507 casos $(35,70 \%)$, seguido por el tercer grupo etario, con 480 ejemplos (33,80\%), y el de primera edad, que registra 433 secuencias $(30,49 \%)$. Se puede apreciar, así, que el DD es el que se utiliza con mayor frecuencia en los tres niveles. En otras palabras, este mecanismo aparece en la primera generación un $32,18 \%$, en la segunda un $32,28 \%$, y en el tercer grupo etario un 35,54\%. En cuanto al DI, podemos observar que es el grupo de la segunda generación quien manifiesta una frecuencia mayor $(44,15 \%)$, seguido de la tercera $(29,51 \%)$ y la primera generación $(26,34 \%)$. Por tanto, la distancia entre el empleo del DD y el DI es ostensible en todos los grupos de edad.

El gráfico 10 muestra el análisis del discurso referido según el nivel de instrucción de los informantes encuestados:

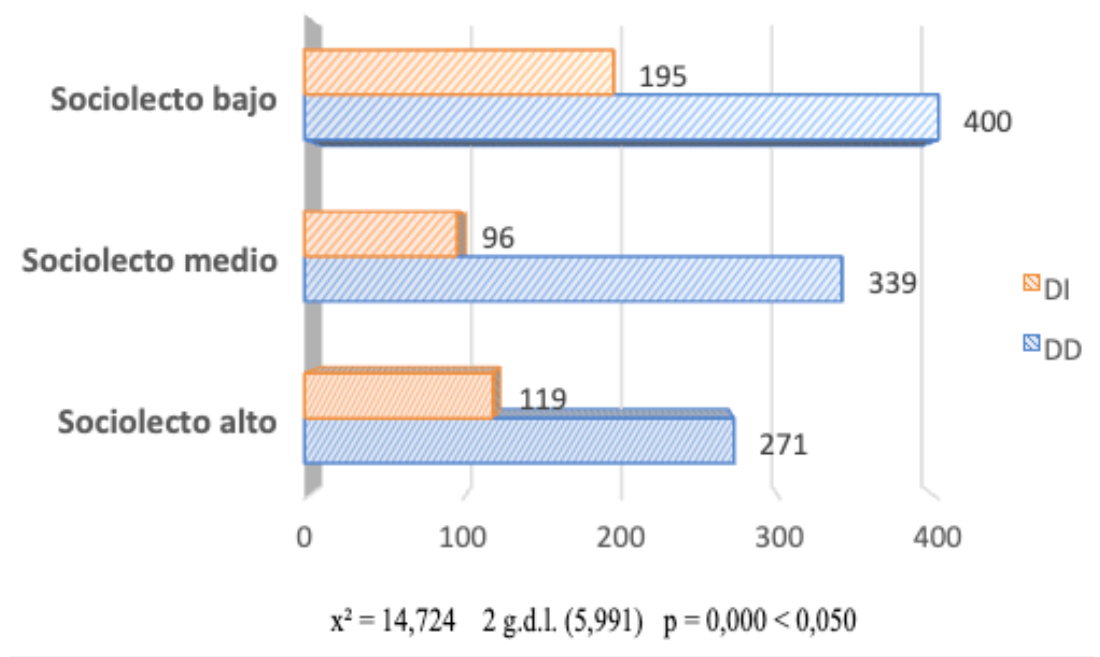

Gráfico 10. Discurso referido y nivel de instrucción

Al correlacionar el empleo del discurso referido con el nivel de instrucción de los informantes, hemos observado que se emplea mayoritariamente en el nivel bajo, esto es, un 41,90\%. En cambio, aparece un 30,63\% en los de 
nivel medio y un 27,46\% en los hablantes de instrucción alta. Por tipo de discurso, el DD se utiliza también con menor frecuencia en el sociolecto alto $(26,83 \%)$ y medio $(33,56 \%)$. Su empleo aumenta visiblemente en el sociolecto bajo que ha registrado un $39,60 \%$ de las ocurrencias. Por consiguiente, el DD manifiesta un patrón ascendente en su comportamiento. El DI, por su parte, muestra un empleo mayor en el sociolecto bajo $(47,56 \%)$, seguido por el alto $(29,02 \%)$ y, por último, el medio $(23,41 \%)$.

El factor estilístico tenor (conocido / no conocido previamente a la entrevista) también ha resultado significativo. En el gráfico 11 ofrecemos información detallada al respecto:

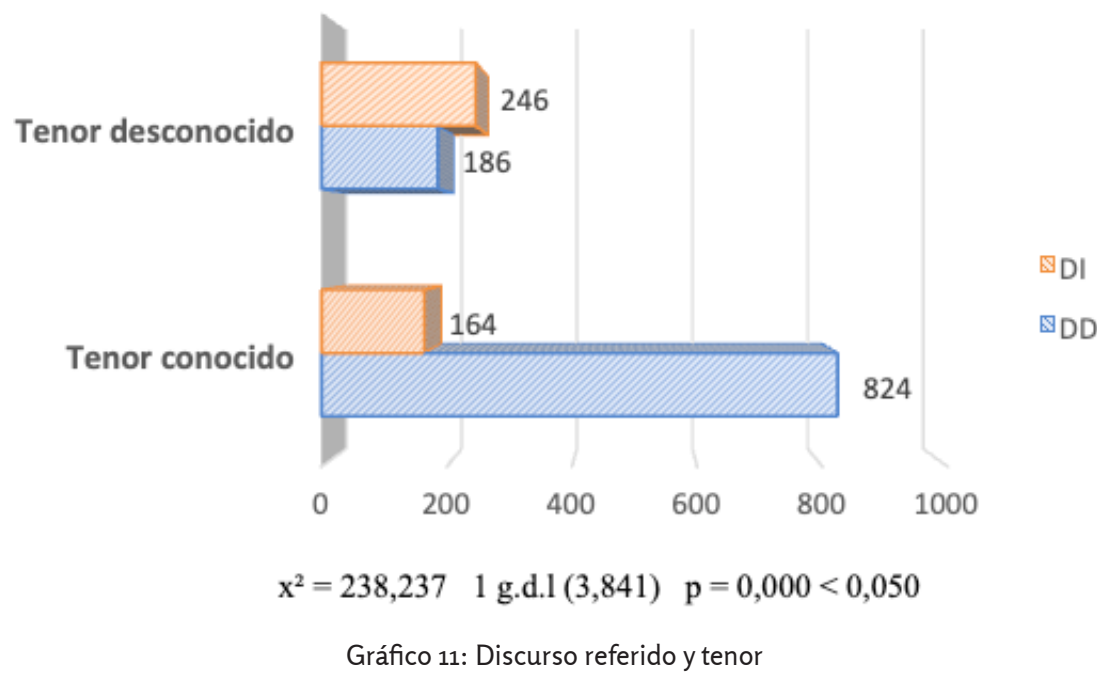

Se ha localizado un número mayor de secuencias de discurso referido cuando el tenor es conocido: $69,58 \%$ vs. 30,42\%. Según el tipo de discurso, se observa que el hablante utiliza el DD en un $81,58 \%$ cuando el otro interlocutor es conocido, y un 18,42\% si los dos participantes en la interacción no se conocen previamente. Con respecto al DI, se manifiesta la tendencia contraria: del total de 410 casos, se ha documentado un $40 \%$ cuando el tenor es conocido y un $60 \%$ si no existe una relación previa entre los participantes en la interacción.

\section{Consideraciones generales}

En relación con el empleo del discurso referido en las 72 entrevistas semidirigidas que constituyen el corpus oral PRESEEA-SE, se manifiesta un uso preponderante de DD $(71,13 \%)$ en comparación con la frecuencia registrada por el DI $(28,87 \%)$.

Esta tendencia parece estar corroborada por diversos estudios sobre el discurso referido en distintas variedades de español. Así, el trabajo de Gallucci $(2013,2018)$ sobre el español hablado en Caracas indica que el DD se usa en un $89 \%$ y el DI en un 11\%; Fernández (2012) también muestra que en el español de Mérida (Venezuela) los hablantes prefieren utilizar el DD. San Martín y Guerrero (2013) encuentran que en la ciudad de Santiago de Chile se usa con mayor frecuencia el DD frente al DI, pues el primero aparece en el $74,2 \%$ de los casos y el segundo en el $25,8 \%$ de las muestras. También 
el trabajo de Grajales Alzate (2018) en el español de Medellín (Colombia) pone de manifiesto que el DD (73\%) constituye la forma más frecuente de reproducir discurso frente al DI, cuyo empleo es mucho menor (27\%).

Según los factores lingüísticos empleados en este estudio, se ha observado que el marco introductor preferido por los sujetos entrevistados es el canónico, esto es, mediante un verbo generalmente conjugado, y decir es el más empleado para introducir tanto el DD como el DI. Estos resultados coinciden con los estudios de Fernández (2012), Gallucci (2009, 2013, 2018b), realizados sobre la reproducción del discurso. Además, los informantes entrevistados prefieren referir las palabras propias y/o ajenas de forma directa con el fin de relatar experiencias personales y/o ajenas, anécdotas, etc. En cambio, la cita impersonal aparece más cuando se presentan argumentos.

Por lo que se refiere a los criterios extralingüísticos considerados en este análisis, hemos visto que están relacionados con el empleo de estos mecanismos de cita en contextos semiformales. Así, son la segunda generación y las mujeres quienes hacen más uso del discurso referido. Nuestros hallazgos con respecto al factor sexo se ven corroborados por los obtenidos en otras investigaciones sobre el mismo tema: San Martín y Guerrero (2013, 272) afirman que en el habla de Santiago de Chile el empleo del discurso referido se manifiesta "preferentemente en las mujeres, aunque se trata de frecuencias de aparición muy cercanas a las registradas en las entrevistas de los hombres que conforman la muestra"; Gallucci (2008) sobre el español caraqueño muestra que las mujeres refieren más que los hombres (55\% vs. 45\%) o Fernández (2012) en su estudio sobre el habla de Mérida indica que el $60 \%$ corresponde a citas de mujeres.

Según el nivel de instrucción de los informantes, este procedimiento citativo se emplea mayoritariamente en el sociolecto bajo. Para el factor estilístico tenor, se ha encontrado mayor predominio de discurso referido cuando los dos hablantes que participan en la interacción se conocen. 


\section{Q Bibliografía}

» Álamo, Francisco. 2013. "El monólogo como modalidad del discurso del personaje en la narración”. Lingüistica y Literatura, 64: 179-201.

" Benavent, Elisa. 2003. “ ¿Por qué contamos nuestras historias cotidianas en estilo directo?”. En Aproximaciones cognoscitivo-funcionales al español. Foro Hispánico, 23, editado por Nicole Delbecque, 11-20. Ámsterdam / Nueva York: Rodopi.

》Benavent, Elisa. 2015. Decir y discurso directo en los relatos de la conversación coloquial. Tesis doctoral. Valencia: Universitat de València.

» Camargo, Laura. 2004. La representación del discurso en la narración oral conversacional. Estudio sociopragmático. Tesis doctoral. Universidad de Alcalá: Alcalá de Henares.

"Casado, Manuel. 2010. "Algunas estrategias para la desautorización del discurso ajeno en la prensa". En Estrategias argumentativas en el discurso periodístico, editado por Concepción. Martínez Pasamar, 69-85. Fráncfort: Peter Lang.

" Casado, Manuel y Alberto de Lucas. 2013. "La evaluación del discurso referido en la prensa española a través de los verbos introductores”. Revista Signos 46: 332-360.

"Fernández, María Fernanda. 2012. "Discurso directo e indirecto en el español de Mérida", Lengua y Habla, 16, pp. 71-85.

" Gallucci, María José. 2009. “Nos fuimos a la casa y mi mamá: '¿estaban lanzándose por la quebrada?’. 'ino mamá!', 'claro que sí'. Estudio piloto de las citas conversacionales en el habla de Caracas”. Núcleo 26: 75-98.

»Gallucci, María José. 2013. "Más sobre el estilo directo e indirecto en el español de Caracas". Lengua y Habla. 17: 89-111.

" Gallucci, María José y Vargas, Kerlys. 2015. "Estilo directo e indirecto en el Corpus Sociolingüístico de Caracas 1987". Anuario de Letras. 3.2: 65-103.

" Gallucci, María José. 2018a. "Estudio sociolingüístico del discurso referido como categoría y continuum en el español hablado de Caracas". Philologica Canariensia. 24: 55-75.

" Gallucci, María José. 2018b. Contribución al estudio del discurso referido en un corpus oral del español americano. Tesis doctoral. Universidad de Zaragoza.

" Girón Alconchel, José Luís. 1988. "La reproducción del discurso en la lengua hablada", en II Simposio Internacional de Semiótica. Lo cotidiano y lo teatral. Vol. I. Oviedo: Servicio de Publicaciones de la Universidad de Oviedo, pp. 203-215.

» Girón Alconchel, José Luís. 1989. "Las formas del discurso referido en el 'Cantar de Mio Cid'”, Boletín de la Real Academia Española, Anejo 44, Madrid.

» Grajales Alzate, Róbinson. 2017. "El discurso referido en el español de Medellín, Colombia”. Lenguaje 45.2: 221-246.

" de Lucas, Alberto. 2017. Polifonía y argumentación: estrategias de introducción de discurso ajeno en un corpus de prensa española actual. Tesis doctoral. Pamplona: Universidad de Navarra.

" Maldonado, Concepción. 1999. "Discurso directo y discurso indirecto”. En Gramática descriptiva de la lengua española, coordinado por Ignacio Bosque y Violeta Demonte, vol. 3: 3551-3595. Madrid: Espasa.

» Méndez, Elena. 1999. “Análisis de la reproducción del discurso ajeno en los textos periodísticos". Pragmalingüística, 7: 99-128. 
» Méndez, Elena. 200o. “Análisis de las formas de introducir el discurso ajeno en los textos periodísticos: el contexto reproductor”. En Lengua, discurso, texto, editado por José Jesús de Bustos Tovar, 2082-2098. Madrid: Visor.

» Perret, Michèle. 1994. L'énonciation en grammaire du texte. París: Nathan.

» Poncharal, Bruno. 2006. "Say un verbe à part - analyse contrastive anglais / français", Discours rapporté(s), Approche(s) linguistique(s) et/ou traductologique(s), 127-141. Arras: Artois Presses Universités.

» Repede, Doina. 2015a. “El discurso directo como estrategia de interpretación de la palabra ajena en los textos periodísticos”. Lengua y Habla 19: 77-92.

» Repede, Doina. 2015b. "Aspectos gramaticales y discursivos de los incisos de cita directa en los textos periodísticos”. En Aplicaciones y enfoques teóricos del análisis del discurso, editado por Alberto de Lucas Vicente et al., 95-117. Pamplona: EUNSA.

» Repede, Doina. 2017b. "Análisis del discurso reproducido en el corpus PRESEEA-SeviIla: el sociolecto bajo”. En Variación lingüística e identidad en el mundo hispanohablante, editado por José María Santos Rovira, 55-74. Lugo: Axac.

» Repede, Doina. 2018a. Diccionario de verbos transmisores de información en español. Vigo: Academia del Hispanismo.

» Repede, Doina. 2018b. "El uso del discurso referido en el corpus PRESEEA-Sevilla: el sociolecto alto". Anuario de letras, 6.1: 187- 218.

» Repede, Doina. (ed.) 2019. El español hablado en Sevilla. Corpus PRESEEA-Sevilla. Vol. I. Hablantes de instrucción alta. Sevilla: Editorial Universidad de Sevilla.

» Repede, Doina. En prensa. El español hablado en Sevilla. Corpus PRESEEA-Sevilla. Vol. II. Hablantes de instrucción baja. Sevilla: Editorial Universidad de Sevilla.

» Ruano San Segundo, Pablo. 2015. "Verbos de habla en textos literarios: propuesta metodológica para su localización y apuntes en torno a su función caracterizadora en Pickwick Papers, de Charles Dickens". En Aplicaciones y enfoques teóricos del análisis del discurso, editado por Alberto de Lucas Vicente et al., 119-140. Pamplona: EUNSA.

»San Martín, Abelardo y Silvana Guerrero. 2013. "Una aproximación sociolingüística al empleo del discurso referido en el corpus PRESEEA de Santiago de Chile". Revista Signos 46.82: 258-282.

»San Martín, Abelardo. 2015. Variación sintáctica y discursiva en el español hablado en Santiago de Chile. Tesis doctoral. Valladolid: Universidad de Valladolid.

» Thompson, Geoff. 1994. Reporting. London: HarperCollins Publishers.

»Van der Houwen, Flor. 2000. “El habla directa vs. indirecta y la organización del discurso”. Foro Hispánico 17 : 27-40.

»Volsik, Paul. 1993. "Évolution de la présence, de la nature et de la place du verbe de parole en anglais et en français”. Palimpsestes, 7. L'ordre des mots, 37-54. Paris : Presses de la Sorbonne Nouvelle. 